\title{
CONSERVAÇÃO E RESTAURAÇÃO FLORESTAL DO PROGRAMA ARBORETUM COMO OPÇÕES DE RESPOSTA À MUDANÇA DO CLIMA, AO ODS 13 E À INDC BRASILEIRA
}

\author{
AUTOR: INGRID CARDOSO DOS SANTOS \\ CO-AUTOR: FREDERICO MONTEIRO NEVES \\ CO-AUTOR/ORIENTADOR: GUINEVERRE ALVAREZ MACHADO DE MELO GOMES
}

\begin{abstract}
Resumo: Os efeitos das mudanças climáticas estão cada vez mais presentes, o que demanda importantes movimentos para sua mitigação e adaptação. A Agenda 2030 é uma proposta das Nações Unidas para que os países direcionem seus movimentos em busca do desenvolvimento sustentável e seu ODS 13 aborda a ação contra a mudança global do clima. Para compreender este desafio em cenários regionais e locais, esta diretriz internacional se alia a estudos científicos do IPCC e às previsões de ações nacionais, como a iNDC. Dessa forma, o objetivo deste plano é investigar de que forma o Programa Arboretum contribui para que estas propostas internacionais sejam alcançadas a partir do nível local/regional. Utilizou-se, para tanto, de pesquisa bibliográfica e consulta a dados primários (como entrevistas, grupos focais e observação), comparando as metas e diretrizes internacionais com as que são desenvolvidas direta ou indiretamente pelo Programa, em Teixeira de Freitas e região. Os resultados obtidos sinalizam a importância do Programa para extremo sul da Bahia com ações em florestamento e reflorestamento da mata atlântica, gestão sustentável do uso da terra e revitalização de solos degradados, além de auxiliar nas metas brasileiras de enfrentamento das mudanças climáticas.
\end{abstract}

Palavras-chave: Adaptação, Mudanças climáticas, Mata Atlântica, Programa Arboretum. 